\title{
Influence of ultrasonic vibration on discrete media filled tubes during forward extrusion
}

\author{
Xia Chen', Tong Wen ${ }^{2}$, Haoxing Tang ${ }^{3}$ \\ College of Materials Science and Engineering, Chongqing University, Chongqing, China \\ ${ }^{2}$ Corresponding author \\ E-mail: ${ }^{1}$ chenxia@cqu.edu.cn, ${ }^{2}$ wentong@cqu.edu.cn, ${ }^{3} 303996614 @ q q . c o m$
}

Received 25 December 2018; received in revised form 16 April 2019; accepted 29 May 2019 DOI https://doi.org/10.21595/jve.2019.20475

Check for updates

Copyright $(2019$ Xia Chen, et al. This is an open access article distributed under the Creative Commons Attribution License, which permits unrestricted use, distribution, and reproduction in any medium, provided the original work is properly cited.

\begin{abstract}
The coupled deformation of composite structures of discrete media filled thin-walled tubes under the action of forces is a complicate mechanical process, especially when it is superimposed with external vibration. A Jenike shear cell connected with an ultrasonic exciting system was used to test the friction angles of the aggregations of ferric powder and steel ball under quasi-static and high frequency vibration conditions; then forward extrusion of Al6061 tubes filled with these discrete materials under different conditions were examined by experiment and numerical simulation. The results showed that the friction angles of both the discrete materials decreased under vibration, and those of the powders were reduced more, indicating that the "surface effect" of vibration on the particles with smaller granularity is more obvious. Under the combining action of "volume" and "surface" effects of vibration, the extrusion loads of the structures significantly decrease with the superposition of vibration, meanwhile the loads of the tubes filled with powders reduced more. With the imposed vibration, the density of fillers after forming are higher and the tube wall thickness distribution is more uniform.
\end{abstract}

Keywords: powder in tube, extrusion, discrete media, vibration, deformation.

\section{Introduction}

Since the pioneering work of Blaha and Langenecker $[1,2]$ for superimposing mechanical vibration on the monocrystal zinc during tensile tests, a great number of studies had been conducted to reveal the effect of vibration on the plastic deformation of metals [3-6]. So far the main understanding regarding the mechanism is twofold [7-9]: the volume effect and the surface effect. Volume effect reflects the influence of vibration on plastic flow behaviors, such as the deformation resistance etc., while the latter refers to the influence of vibration on tribology properties, usually showing a reduction of interfacial friction. How to make use of these effects of vibration, especially the high frequency vibration of power ultrasonic, and then realize some specific purposes in various metal forming processes, have received huge attention in recent years [10-13].

The composite structure of discrete media filled hollow profiles is frequently encountered in industrial environment, for instance, the PIT (powder in tube) methods for production of superconducting wires $[14,15]$, the solid granule medium forming [16], and others [17-21]. Integral deformation of these types of structures is a complicated mechanical process, coupled with elastic-plastic deformation of mother tube, flow of inner media, and the interactions between filler and tube wall as well. In the manufacturing of superconductive wires by PIT, defects/failures like uneven powder distribution and even fracture of wires often take place during operation if the processing parameters are improperly selected. To improve the quality of the wires, sometimes vibration is applied during the drawing processes of tubes [22]. However, since the coupled deformations of composite structures of discrete media filled hollow profiles are affected by multi-factors, especially when external vibration is superposed, so far the relevant knowledges from the aspects of theoretical studies and engineering application - are severely lacking [23-27]. Therefore, this paper investigated the forward extrusion of thin-walled metallic tubes, filled with 
loose particles, under quasi-static and vibration states by using physical experiment and numerical simulation. Forming load, deformation characteristics, densification and uniformity of the fillers after forming were examined.

\section{Analysis method}

\subsection{Experiment}

Fig. 1 shows the experimental setup for the extrusion of tubes under various conditions. The cone angle of the die is $15^{\circ}$, and the outlet diameter is $16 \mathrm{~mm}$. To apply vibration on the die and workpiece, an ultrasonic exciter was connected to the lateral side of the die by rigid joints, and then the high frequency vibration can be transmitted to the composite structure. The output energy (amplitude) of the ultrasonic vibration can be adjusted on the ultrasonic generator. Unless otherwise stated, the output vibrating amplitude in the tests is $50 \% \mathrm{~A}$, where $A$ denotes the maximum output amplitude of the ultrasonic device. Specific structure of the device and relevant vibrating parameters can be referred in the author's previous works [3].
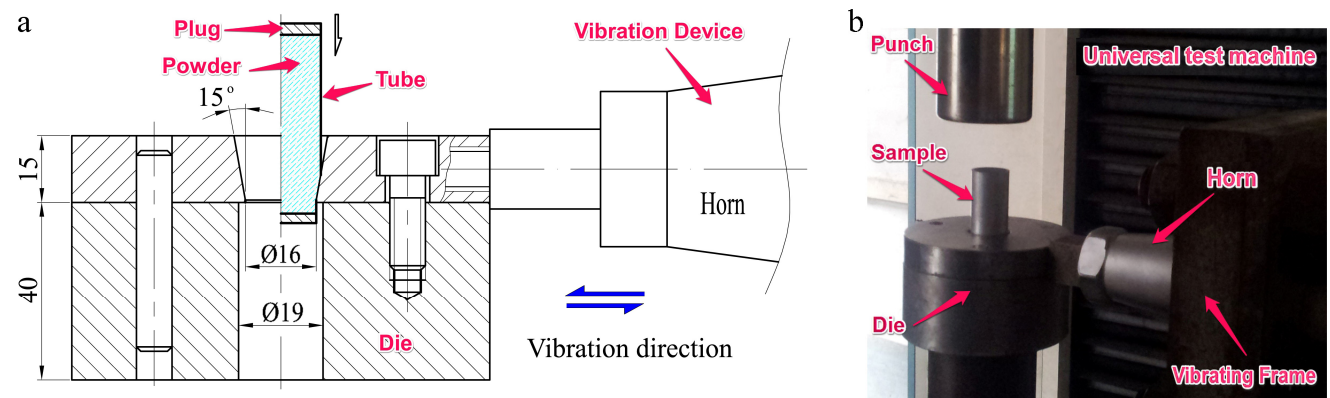

Fig. 1. Vibrating extrusion of thin-walled tube with filler. a) Schematic of the experiment setup;

b) photograph of the experiment setup

A16061 tubes with size of $\Phi 20 \mathrm{~mm} \times 70 \mathrm{~mm} \times 1.5 \mathrm{~mm}$ were used in the experiments. Before extrusion, the lower ends of the mother tubes were pressed into the die in advance, reducing the diameter and forming a cone-shaped end that is in accordance with the concave of die, as shown in Fig. 2(a). The fillers are reduced ferric powders (about $0.075 \mu \mathrm{m}$ in diameters), and chrome molybdenum alloy steel balls with diameter ranging from 0.3 to $0.8 \mathrm{~mm}$ and 40-50 HRC in hardness. To ensure that the fillers can be reliably sealed in the tubes during forming, Al7050 cylinder plug were put into the ends of each tube. $\mathrm{MoS}_{2}$ was used as lubricant at the interface of the tube and die. The experiments were performed on a SANS CMT 5105 universal material testing machine.

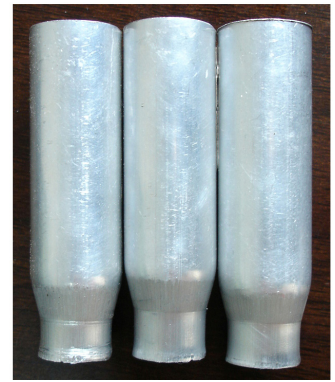

a)

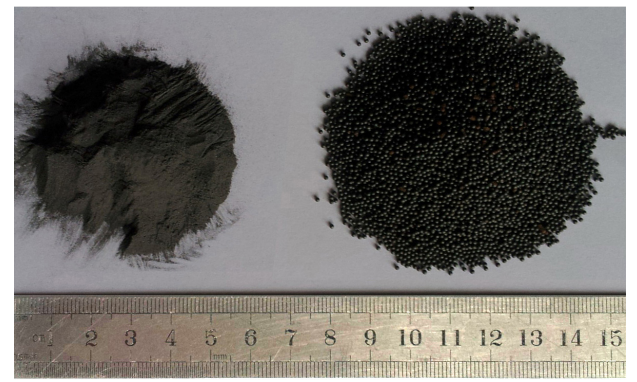

b)

Fig. 2. a) Al6061 tubular samples; b) fillers (ferric powder and steel balls) in the experiments

In the generalized plastic theories, friction angle plays an important role in the description of 
plastic properties of discrete media. During the extrusion processes superimposed with vibration, the inside fillers are simultaneously subjected to the actions of static compaction and dynamic vibration. To carry out the theoretical analysis, variation of the friction angles of the discrete materials under different conditions is needed to know. In the current study, the friction angles of the ferric powders and steel balls were measured on a Jenike shear cell (model ZBQ-4), where the same ultrasonic exciting unit used in the extrusion is attached, as shown in Fig. 3. The testing procedure was in accordance with the ASTM standard D6128-16 [28].

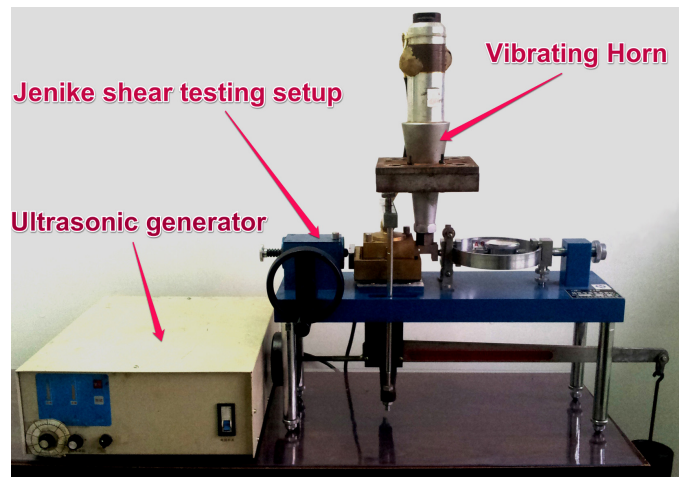

Fig. 3. The modified Jenike shear cell for testing discrete media under vibration compaction

\subsection{Theoretical analysis}

Abaqus/Explicit was used to simulate the extrusion of discrete media filled tubes. Geometries of the models in the calculations are consistent with those in the experiments. The main parameters of the fillers used in the studies are listed in Table 1.

Table 1. The mechanical parameters of granular materials

\begin{tabular}{|c|c|c|}
\hline & Fe powder & Steel ball \\
\hline Density at lose state $\left(\mathrm{kg} / \mathrm{m}^{3}\right)$ & 2.55 & 4.33 \\
\hline Elasticity modulus $(\mathrm{MPa})$ & 14000 & 5900 \\
\hline Poisson's ratio & 0.3 & 0.33 \\
\hline Friction angle $\theta\left(^{\circ}\right)$ & 35.8 & 31.7 \\
\hline Dilation angle $\left(^{\circ}\right)$ & 0 & 0 \\
\hline
\end{tabular}

In theory, once the vibration is applied on the structure, the two effects of vibration would act on both the tubes and fillers. For numerical simulations, all the effects should be considered and therefore the influence of high frequency excitation on extrusion of powder-in-tube structures can be accurately reflected. The "volume effect" performs in two ways: the influence on the plastic deformation of tube wall, which can be directly tested by tensile test under vibration [3]; and the influence of vibration on the fillers. In the light of the fact that the plastic deformation of single particle of the fillers is negligible during extrusion, the influence of "volume effect" on the deformation of particles can be omitted. As for the "surface effect", three types of interface, including those between tube/die, tube/powder and powder/powder, should be dealt with. In the current study, friction forces on the interfaces of tube/die and tube/powder were characterized by means of Coulomb's friction law. The friction coefficient $\mu$ was set to 0.2 for quasi-static extrusion, and 0.1 for vibrating extrusion. The friction angles of discrete media under vibration can be measured by the aforementioned special-designed Jenike shear cell.

In the following, specific technologies used for dealing with the movement and material properties will be described.

(1) The mother tubes move downward at a slow and constant velocity $(2 \mathrm{~mm} / \mathrm{s})$ during forming, and the fillers deform with the tubes as a follower. A reciprocating movement according 
to the sine law, representing the vertical component of high-frequency vibration, is superimposed on the velocity [29-30]. Therefore, the relationship between displacement $S$ and time $t$ is:

$S=A \sin [2 \pi f(t)]+2 t$

where $A$ and $f$ are the amplitude and frequency of the vibration. In the calculations, according to the experiment condition, they are set to $0.001 \mathrm{~mm}$ and $1.5 \mathrm{KHz}$, respectively.

(2) In the FEM simulation, the "volume effect" of vibration on the material properties of mother tubes, namely Al6061, can be represented in the constitutive equations derived from the stress-strain curves of vibration assisted tensile tests [3,30]:

$\sigma=\sigma_{s}+B \varepsilon^{n}=50+738.2 \varepsilon^{0.44}$.

(3) The non-continuum material of the aggregated particles is assumed to be compressible continuous body in the theory of generalized plastic mechanics. The yield behavior can be described by the Drucker-Prager criterion [31-34]:

$f\left(I_{1}, \sqrt{J_{2}}\right)=\sqrt{J_{2}}-a I_{1}-k=0$,

where $\alpha, k$ are constants related to the cohesion force and friction angle $\theta ; I_{1}$ is the first invariant of stress tensor; $J_{2}$ is the second invariant of deviation stress tensor.

This expression is extended from the von Mises model, and the internal friction characters of discrete media and the influence of hydrostatic stress on plastic flow can be taken into account.

\section{Results and discussion}

\subsection{Effect of vibration on the friction angle of granular materials}

Table 2 is the experimental results of the friction angles of ferric powders and steel balls under quasi-static and ultrasonic vibration conditions. It can be seen that the friction angles of both the discrete materials are reduced under vibration; meanwhile the friction angle of the ferric powders decreases more than that of the steel balls under the action of ultrasonic agitation.

Considering that the elastic-plastic deformation of single particle is very small under the testing load, the effect of material properties on the friction angle can be ignored. Therefore, the main reason for the above phenomenon should be related to the size and shape of the particles. The particle size of ferric powders is much smaller than those of steel balls, thus the total surface area and relative contacting area of the powders are much larger, and then the "surface effect" is much more obvious.

Table 2. The friction angle of granular materials under various conditions

\begin{tabular}{|c|c|c|}
\hline \multirow{2}{*}{} & \multicolumn{2}{|c|}{ Friction angle $\theta\left(^{\circ}\right)$} \\
\cline { 2 - 3 } & Ferric powder & Steel ball \\
\hline Without vibration & 35.8 & 31.7 \\
\hline With vibration & 19.1 & 24.9 \\
\hline
\end{tabular}

\subsection{Effect of vibration on the deformation of particle filled tubes in forward extrusion}

\subsubsection{Overall deformation and forming load}

Fig. 4 is the experiment and simulation results of the ferric powder filled tubes after extrusion under quasi-static and ultrasonic vibration states. It can be seen that the outline of the tube formed under vibration is more uniform, and the results of numerical simulation agree closely with the experiments. 


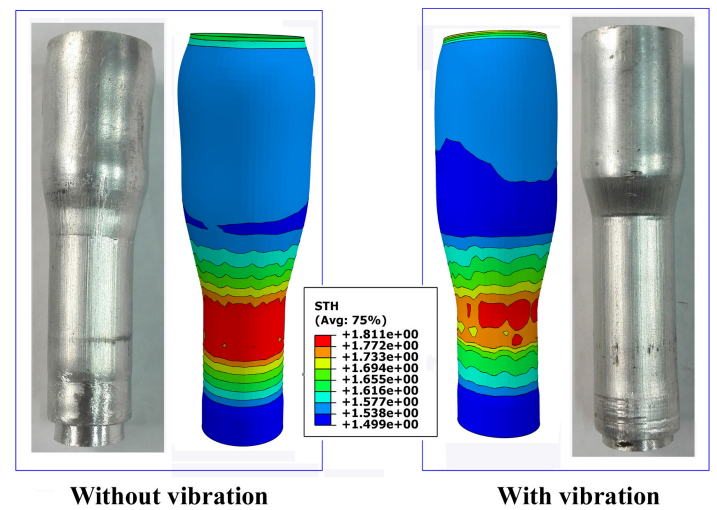

Fig. 4. Deformation of the ferric powder filled Al6061 tubes after extrusion

Fig. 5 shows the load-stroke curves of the powder-in-tube structures during forward extrusion. It can be seen that, no matter there is lubricant or not, the loads decrease immediately once the ultrasonic vibration is added. Moreover, the load decreases more when vibrating amplitude is larger. The load recovers as soon as the vibration is unloaded. The load deceases by about 20 percent with the usage of lubrication on the interfaces of the tube and die cavity, while it is reduced by nearly 18 percent with the assistance of vibration under non-lubrication state. The load is totally reduced by about $38 \%$ when lubrication and vibration are applied simultaneously, showing an additivity of the load reduction under two conditions.

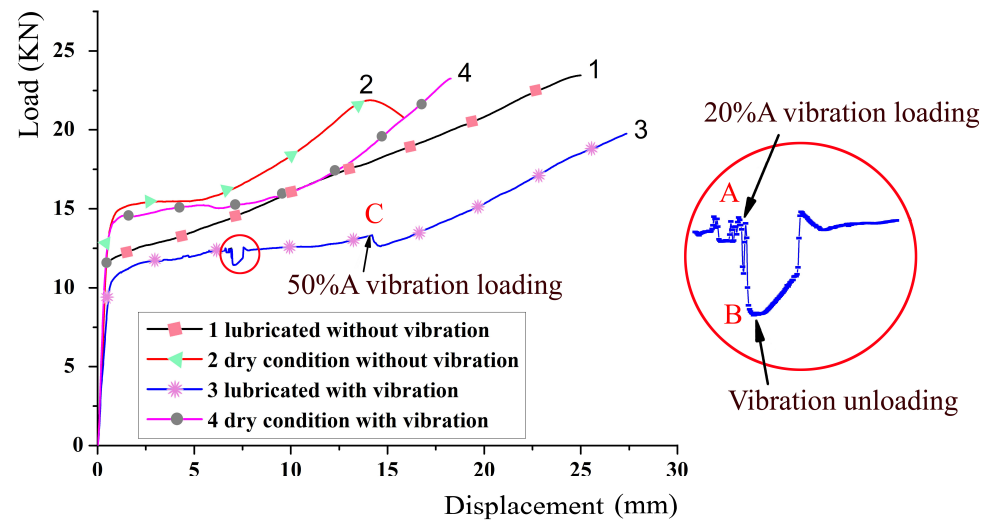

Fig. 5. Load-stroke curves of the tubes filled with ferric powders under various extrusion conditions

For the intermittent vibration, as shown in Fig. 5 (Curve No. 3), it can be seen that as soon as the ultrasonic wave is applied the load at point $\mathrm{A}$ drops rapidly to point $\mathrm{B}$. With the release of vibration, the load rises slowly and recovers to static situation. At point $\mathrm{C}$, the load reduces again when the vibration was added, and the load steadily increases at a lower level compared to the normal extrusion without vibration. At different compaction stages, effects of vibration on the fluidity of powders are different, since the density of the filled powders is changing.

For the extrusion of tubes filled with steel balls, rearrangement of ball position is the main deformation behavior of the fillers at the mid stage, which has less impact on the tube deformation and then the loads keep almost stable, as shown in Fig. 6. With the extrusion going on the volume of tube cavity decreases, the balls are compacted tightly and the pressure increases sharply. Applying ultrasonic vibration can reduce the load by nearly $7.7 \%$, which is less than that of the tubes filled with small powders. This is consistent with the aforementioned results of the friction angles of the two discrete materials, namely, the effect of vibration on the deformation of small particles is more obvious. 


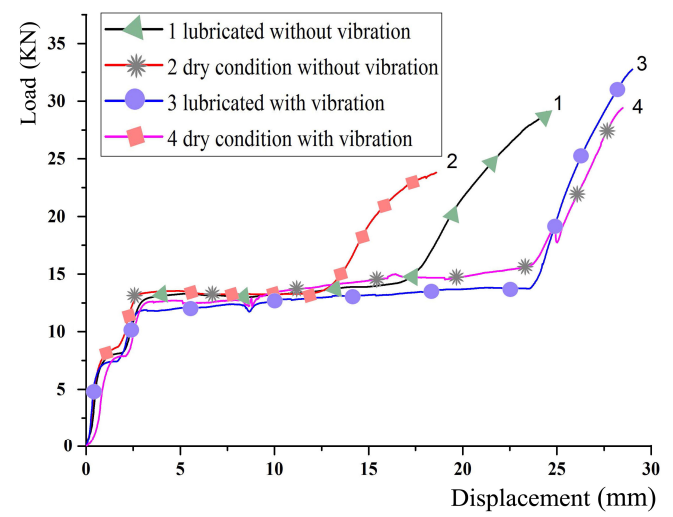

Fig. 6. Load-stroke curves of the steel-ball filled tubes under various extrusion conditions

\subsubsection{Force on the fillers during extrusion}

Fig. 7 shows the forces inside the fillers during forward extrusion; Fig. 8 is the simulated results of hydrostatic stress distribution of the ferric powders. It can be seen that Regions 2 and 3 , with large deformation subjected, have higher pressure. Undoubtedly, the inhomogeneity of pressure would incur uneven density distribution of the fillers after forming.
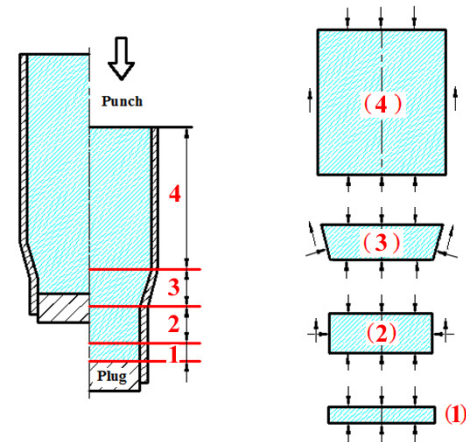

Fig. 7. Schematic diagram of the forces inside the filler during extrusion

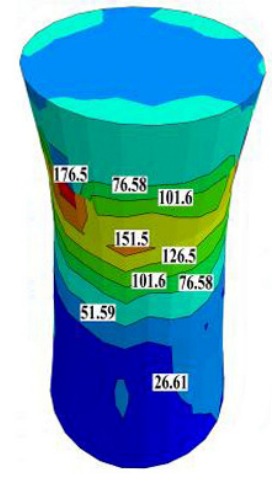

a) Without vibration

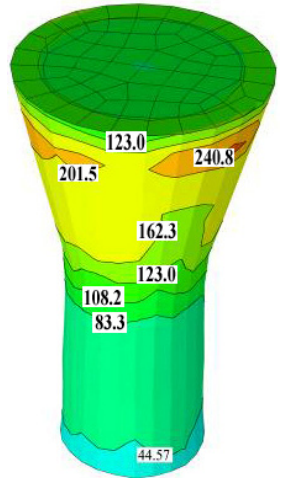

b) With vibration

Fig. 8. Hydrostatic stress distribution of the filled powders during quasi-static/vibrating extrusion (omitting Region 4). Unit: Pa

Stress state inside the tubes during extrusion has huge influence on the density (or hardness) distribution of the fillers after forming. Fig. 9 shows the variation of hydrostatic stress of the 
powders at the bottom section of conical die (Node 155). It can be seen that with the reduction of tube diameter and inner cavity volume, the hydrostatic stress of the filler increases, causing a compaction of the powder. Without vibration, the pressure increases slowly at the beginning of extrusion. Since vibration can enhance the flowing capacity of particles, the pressure increases immediately at the earlier stage when ultrasonic vibration was added.

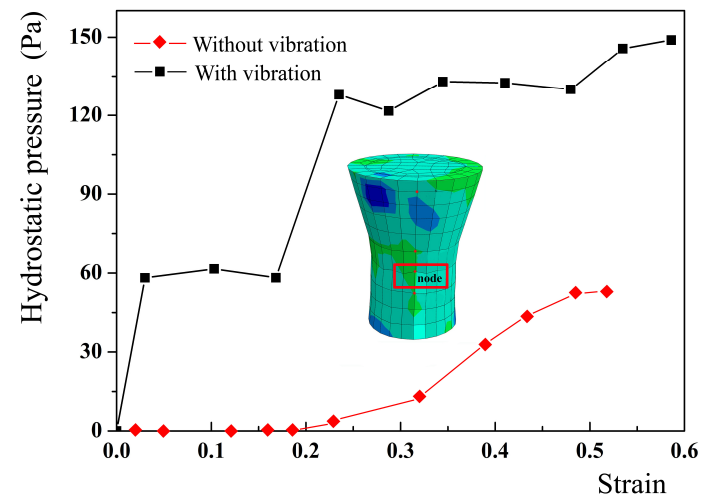

Fig. 9. Hydrostatic pressure vs. strain of powders during extrusion

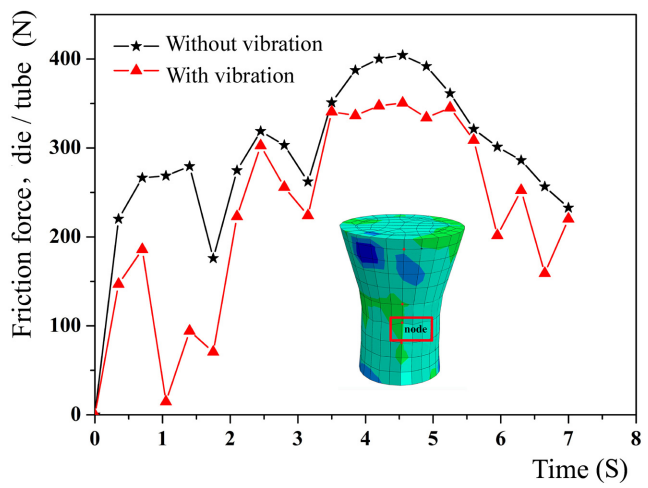

a)

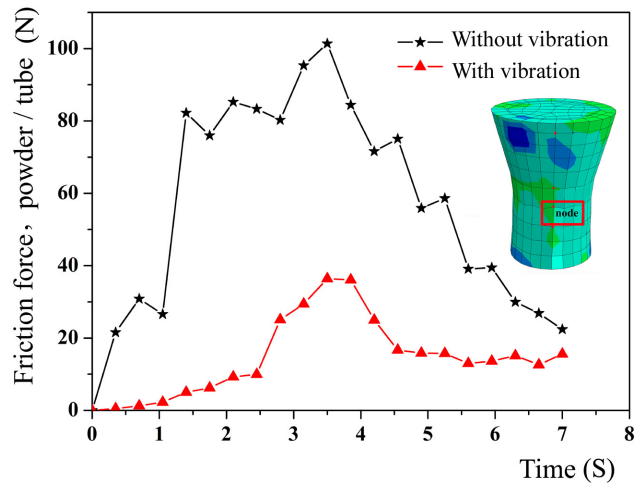

b)

Fig. 10. Friction under different conditions

Friction has huge influence on the extrusion load and compaction behavior of fillers. Fig. 10 shows the FEM results of friction-time curves of the powders at a specific point (node 155). As can be seen, the friction between the interfaces of die/tube and tube/powder increase with the stroke. After passing through the conical section of the die, the surface friction decreases. The friction is reduced when vibration is superimposed, meanwhile the friction of the powder/tube interfaces decreases more.

\subsubsection{Densification of the fillers}

The compaction degree of the fillers is closely related to the stress state during extrusion. Under vibration condition, the significant reduction in friction at the interfaces of tube/die, tube/particle and particle/particle is beneficial to the compaction of fillers. Fig. 11 shows the experimental results of the hardness of ferric powders after extrusion inside the tubes. The extruded tubes together with the fillers were cut into four sections, and the hardness on the cross-sections of the powder beds was measured. It can be seen that, for various forming conditions there are similar trend of hardness distribution. Hardness of the Region 3 is the largest, where the deformation is also severe. Basically, hardness of the fillers after extrusion is 
corresponding to the hydrostatic stress distribution, as shown in Fig. 8. The hardness value was improved with the application of lubrication and ultrasonic vibration during extrusion and, with the usage of vibration it can be improved even more. The results proved that ultrasonic vibration is beneficial to improve the density in PIT treatments.

It was also found that whether there is vibration or not, the filler of steel balls with large particle size and high hardness is unable to densify, and after extrusion it is still in a discrete state.
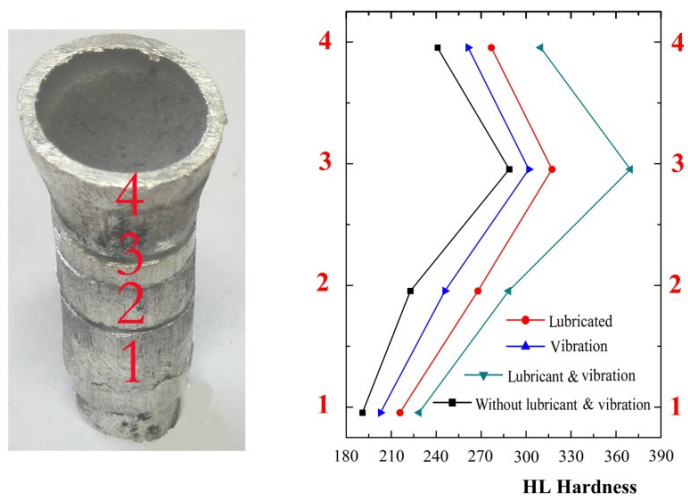

Fig. 11. Hardness distribution of the Fe powder beds after extrusion in the tube under different conditions

\subsubsection{Variation of tube wall thickness}

It can be seen from Fig. 4 that wall thickness of the powder filled tubes after extrusion is more uniform with the application of ultrasonic vibration. Fig. 12 shows the thickness distribution of the steel ball filled tubes after extrusion. It can be seen that the areas with large deformation have the largest thickness. As a whole, wall thickness distributions of the tubes formed with lubrication and vibration are more uniform. Moreover, the tube surfaces after extrusion are better with the application of vibration, meanwhile the occurrence of instability is also less due to the lower load.

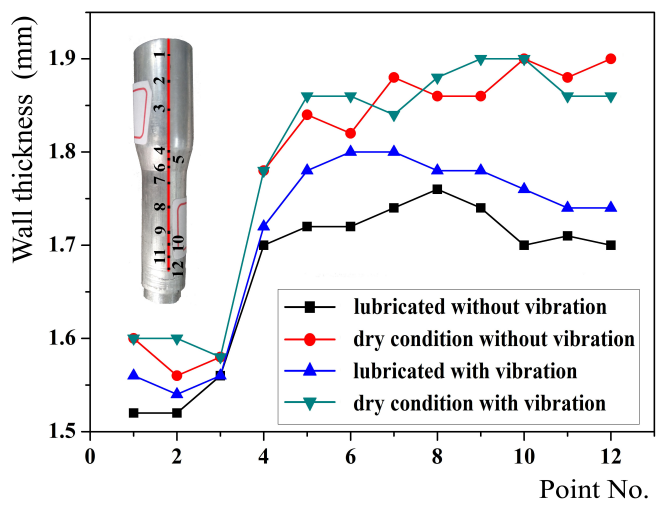

Fig. 12. Experiment results of thickness distribution of the tubes filled with steel ball after extrusion

\section{Conclusions}

This paper studied the forward extrusion of discrete media filled A16061 tubes under the states of quasi-static and ultrasonic vibration. The effect of vibration on the forming load, interfacial friction, distribution of hydrostatic stress and filler density were examined. The main conclusions are as follows:

1) Friction angles of the aggregations of ferric powders and steel balls are all reduced under vibration, since vibration is helpful to the flow of discrete media. However, the friction angle of 
ferric powders decreases more, indicating that vibration has larger effect on the tribological behavior of small particles, and thus the "surface effect" is more obvious.

2) The extrusion load of discrete media filled tubes can be dramatically reduced with the superposition of vibration, and the reduction increases with the vibrating amplitude. Under the same amplitude, the load of the tubes filled with small powders decreases more.

3) As a whole, the hydrostatic pressure of the fillers inside tubes is greater under vibrating conditions, and the pressure increases fast with the superposition of vibration during extrusion. Compared with the deformation of dense metals, the "surface effect" of vibration on the flow of discrete materials is amplified, since the total surface area is dramatically enlarged.

4) It was found that both the lubrication and vibration can increase the density of fillers after forming, and the vibration can increase the density even more. Furthermore, due to the joint effect of "volume effect" and "surface effect" of vibration, the wall thickness distribution of the formed tubes is more uniform.

\section{Acknowledgement}

The authors would like to acknowledge the funding from the National Natural Science Foundation of China (No. 51575066).

\section{References}

[1] Blaha F., Langenecker B. Elongation of zinc monocrystals under ultrasonic action. Die Natur Wissenschafen, Vol. 42, Issue 20, 1955, p. 556.

[2] Langenecker B. Effect of ultrasound on deformation characteristics of metals. IEEE Transactions on Sonics and Ultrasonics, Vol. 13, Issue 1, 1966, p. 1-8.

[3] Wen T., Wei L., Chen X., Pei C. L. Effects of ultrasonic vibration on plastic deformation of AZ31 during the tensile process. International Journal of Minerals, Metallurgy and Materials, Vol. 18, Issue 1, 2011, p. 70-75.

[4] Kumar V. C., Hutchings M. Reduction of the sliding friction of metals by the application of longitudinal or transverse ultrasonic vibration. Tribology International, Vol. 37, Issue 10, 2004, p. 833-840.

[5] Hung J. C., Tsai Y. C., Hung C. H. Frictional effect of ultrasonic- vibration on upsetting. Ultrasonics, Vol. 46, Issue 3, 2007, p. 277-284.

[6] Siddiq A., Sayed T. Acoustic softening in metals during ultrasonic assisted deformation via CP-FEM. Materials Letters, Vol. 65, Issue 2, 2011, p. 356-359.

[7] Ashida Y., Aoyama H. Press forming using ultrasonic vibration. Journal of Materials Processing Technology, Vol. 187, Issues 188-3, 2007, p. 118-122.

[8] Djavanroodi F., Ahmadian H., Koohkan K., Naseri R. Ultrasonic assisted-ECAP. Ultrasonics, Vol. 53, Issue 6, 2013, p. 1089-1096.

[9] Bunget C., Ngaile G. Influence of ultrasonic vibration on micro-extrusion. Ultrasonics, Vol. 51, Issue 5, 2011, p. 606-616.

[10] Siegert K., Ulmer J. Superimposing ultrasonic waves on the dies in tube and wire drawing. Journal of Engineering Materials and Technology, Transactions of the ASME, Vol. 123, Issue 4, 2001, p. 517-523.

[11] Murakawa M., Jin M. The utility of radially and ultrasonically vibrated dies in the wire drawing process. Journa1 of Materials Processing Technology, Vol. 113, Issues 1-3, 2001, p. 81-86.

[12] Petruzelka J., Sarmanova J., Sarman A. The effect of ultrasound on tube drawing. Journal of Materials Processing Technology, Vol. 60, Issues 1-4, 1996, p. 661-668.

[13] Jimma T., Kasuga Y., Iwaki N., et al. An application of ultrasonic vibration to the deep drawing process. Journal of Materials Processing Technology, Vol. 80-81, 1998, p. 406-412.

[14] Jiang J., Abell J. S. Effects of precursor powder particle size on critical current density and microstructure of Bi-2223/Ag tapes. Physica C, Vol. 296, 1998, p. 13-20.

[15] Gao H. T., Liu X. H., Qi J. L., Ai Z. R., Liu L. Z. Microstructure and mechanical properties of $\mathrm{Cu} / \mathrm{Al} / \mathrm{Cu}$ clad strip processed by the powder-in-tube method. Journal of Materials Processing Technology, Vol. 251, Issue 1, 2018, p. 1-11. 
[16] Dong G. J., Zhao C. C., Cao M. Y. Process of back pressure deep drawing with solid granule medium on sheet metal. Journal of Central South University, Vol. 21, Issue 7, 2014, p. 2617-2626.

[17] Wen T., Liu Q., Huang Q., Ou W., Feng J. Q. Deformation and densification behavior of discrete media filled thin-walled tubes during forward extrusion. Transactions of Nonferrous Metals Society of China, Vol. 26, Issue 8, 2016, p. 2162-2169.

[18] Duarte I., Vesenjak M., Krstulovic Opara L. Dynamic and quasi-static bending behaviour of thin-walled aluminum tubes filled with aluminum foam. Composite Structures, Vol. 109, Issue 6, 2014, p. 48-56.

[19] Darvizeh A., Darvizel M., Ansari R., Meshkinzar A. Effect of low density, low strength polyurethane foam on the energy absorption characteristics of circumferentially grooved thick-walled circular tubes. Thin-Walled Structures, Vol. 71, Issue 13, 2013, p. 81-90.

[20] Wang X., He M., Zhu Z., Xue K., Li P. Influence of twist extrusion process on consolidation of pure aluminum powder in tubes by equal channel angular pressing and torsion. Transactions of Nonferrous Metals Society of China, Vol. 25, Issue 7, 2015, p. 2122-2129.

[21] Schneider S. P. Axially loaded concrete-filled steel tube. Journal of Structural Engineering, Vol. 124, Issue 10, 1998, p. 1125-1138.

[22] Graff K., Tomsic M., Collings E. Ultrasonic drawing of composite superconducting wire. The 32nd Annual UIA Symposium, New York, 2002.

[23] Rosato A., Blackmore D. L., Zhang N., Lan Y. A perspective on vibration-induced size segregation of granular materials. Chemical Engineering Science, Vol. 57, Issue 2, 2002, p. 265-275.

[24] Zainuddin M., Yasuda M., Liu Y. H., Maruyama H., Matsusaka S. Development of vibration shear tube method for powder flowability evaluation. Powder Technology, Vol. 217, Issue 2, 2012, p. $548-553$.

[25] Tai C. H., Hsiau S. S. Dynamic behaviors of powders in a vibrating bed. Powder Technology, Vol. 139, Issue 3, 2004, p. 221-232.

[26] Wu S., Wu X., Xu B., Cheng R., Luo F., Ruan S. A micro-ultrasonic powder moulding method to fabricate Sn-Bi alloy micro parts. Journal of Materials Processing Technology, Vol. 214, Issue 11, 2014, p. 2668-2675.

[27] Barletta D., Poletto M. Aggregation phenomena in fluidization of cohesive powders assisted by mechanical vibrations. Powder Technology, Vol. 225, Issue 7, 2012, p. 93-100.

[28] ASTM-D6128-16 - Standard Test Method for Shear Testing of Bulk Solids Using the Jenike Shear Cell. West Conshohocken, ASTM International, 2016.

[29] Siddiq A., El Sayed T. Ultrasonic-assisted manufacturing processes: Variational model and numerical simulations. Ultrasonics, Vol. 52, Issue 4, 2012, p. 521-529.

[30] Daud Y., Lucas M., Huang Z. H. Modelling the effects of superimposed ultrasonic vibrations on tension and compression tests of aluminum. Journal of Materials Processing Technology, Vol. 186, Issue 1, 2007, p. 179-190.

[31] Azami A. R., Khoei A. R. 3D computational modeling of powder compaction processes using a three-invariant hardening cap plasticity model. Finite Elements in Analysis and Design, Vol. 42, Issues 8-9, 2006, p. 792-807.

[32] Lee H. C., Chao C. G., Liu T. F., Lin C. Y., Wang H. C. Effect of temperature and extrusion pass on the consolidation of magnesium powders using equal channel angular extrusion. Materials Transactions, Vol. 54, Issue 5, 2013, p. 765-768.

[33] Derakhshandeh H. R., Jenabali J. A. An investigation on the capability of equal channel angular pressing for consolidation of aluminum and aluminum composite powder. Materials and Design, Vol. 32, Issue 6, 2011, p. 3377-3388.

[34] Lee K. H., Lee J. M., Kim B. M. Densification simulation of compacted Al powders using multi-particle finite element method. Transactions of Nonferrous Metals Society of China, Vol. 19, Issue 1, 2009, p. 68-75.

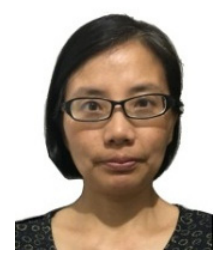

Xia Chen received Master degree in Chongqing University, Chongqing, China, in 2000. Now she is an Associated Professor in Chongqing University. Her current research interests include mechanical designing and materials processing. 
INFLUENCE OF ULTRASONIC VIBRATION ON DISCRETE MEDIA FILLED TUBES DURING FORWARD EXTRUSION.

Xia Chen, TONG Wen, HaOXING TANG

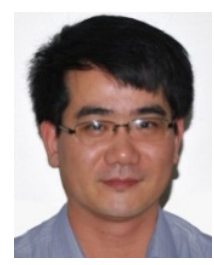

Tong Wen received his Ph.D. degree from Chongqing University, Chongqing, China, in 1999. Now he is a Professor in Chongqing University. His current research interests include advanced materials processing technologies and numerical simulation methods in metal forming.

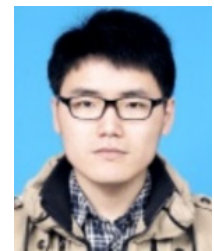

Haoxing Tang received his Master degree in Chongqing University, Chongqing, China, in 2016. He is now a Ph.D. candidate student in Chongqing University. His primary research interest is advanced metal forming technologies. 